\title{
Why museum and art gallery publishing?
}

\author{
Chapter 1 of: Museum and gallery publishing: From theory to case study [ISBN: 9781472437143] \\ (Routledge, 2019)
}

\section{Sarah Anne Hughes, Oxford Brookes University}

\begin{abstract}
[Abstract: The rationale and scope of the book is explained. Museum and art gallery publishing is an interdisciplinary topic with potential contributions to the fields of publishing studies and museum studies. The topic is examined from a theoretical position that views production processes as creating resources for communication with audiences and reception by visitors and readers as predicated on individual appropriation of these resources. Publishing contributes to communication strategies for collections as both a commercial enterprise and an agent of cultural exchange. The discussions are primarily concerned with printed books but digital resources are considered where they are a primary means of dissemination of intellectual property and academic research.]
\end{abstract}

Why do museums and art galleries publish books? Exhibitions, public programming and websites offer exciting and innovative ways to communicate with their publics. So, what do books offer that these forms of audience engagement do not? And, what purposes continue to drive the publication of printed materials when collections can now be shared online? This book attempts answers to these and other questions and aims to explain the relevance of publishing to the cultural, commercial and social contexts of collections and their institutions. In the process a sweep of academic fields will be crossed as the topic is not easily contained by a single disciplinary boundary and touches on book history, literary studies, audience, museum and visitor studies. Communication is essentially the purpose of publishing -that is the dissemination of intellectual property and this practice has a long association with museums, art galleries, scientific collections such as natural history museums and botanic gardens, heritage centres and libraries. In the chapters that follow I consider how, why and to what effect these institutions publish books and offer insights into a topic that has largely passed by current research in both print culture and museum studies. I argue that the production and consumption of printed media within the context of collecting institutions occupies a unique and privileged role in the creation and communication of knowledge built by these cultural and scientific entities. Further, it is not only the textual and illustrative content which constitutes this communicative function; the physical form of the book makes an essential contribution to its role in the museum, not least because of its value as a saleable commodity. I argue for printed books as locales where the authority of museums and galleries is made explicit along with the agency of the associated curatorial scholarship. In the uses that visitors acknowledge of their museum books I locate a willing alignment with the cultural capital of collections.

The absence of any concerted consideration of publishing by museums is surprising given the visibility of books in museum shops, their long history in support of 
collections and their contribution to communication and audience development for museum visitors. Museum publishing takes place in a complex landscape of agents, commercial influences and cultural factors which makes it a potentially rewarding area for investigation with relevance for contemporary museums as well as current publishing. And, museums and art galleries offer a more complex environment than that for commercial publishing. Part of the complexity results from the many different agents, such as curators, directors, artists and sponsors, who affect the production processes. The reception of museum books, that is, their reading, occurs under various institutional influences and to further complicate investigations museums produce many different types of books. Guide books, catalogues-for permanent collections and temporary exhibitions-catalogue raisonnés, monographs, technical reports, themed studies, schools' literature, children's books, artists' monographs, apps, ebooks, limited editions and facsimiles are the main categories, but poetry, fiction, manga and magazines also emanate from collections. There are few museums or art galleries that create all of these although national institutions in the US and Europe take a lead in offering books and digital products that address most of the categories. Institutions with smaller collections, more limited budgets or with a regional or local audience offer at least a guidebook and may aspire to occasional additional publications relating to their collections or exhibitions. To further complicate things, museums co-produce books with other institutions, contract out publishing to commercial companies and sell books produced by other publishers as adjuncts to their exhibitions and public programmes.

However complicated the processes underlying the production of museum books, these objects are naturally associated with collections as authentic carriers of information for intellectual consumption and entertainment. The economic contribution of book sales to many institutions is substantial and it is also as carriers of cultural value that books contribute to collecting institutions. My investigation of museum books recognises that this cultural phenomenon, the book, operates beyond the mere delivery of written language and is consumed for purposes other than reading. It is these many and disparate functions that influence personal responses to reading and to books. Our own histories of reading for entertainment, instruction, relaxation and education affect the ways we respond to and consume books. It is likely that your established reading practices with museum books will likely inform your response to the ideas set out in the following chapters.

Books offer functions beyond communication as carriers of informational text. I argue that within the context of museums and art galleries these functions place books in a unique relationship to the institutions, their staff as producers and their visitors as consumers. Further, the agency and authority of producers in exploiting the intellectual property inherent in collections is made apparent in museum and art 
gallery books. The longevity of books preserves the authority of this field of study as it is construed and constructed by the curation and research of collecting institutions. In the following chapters we will see how this authority and the associated relationships play out to enable producers and consumers to display personal and institutional identities, to mark career progression and to align with the authority associated with collections. My premise is that these uses of the production of museum publishing have to date been overlooked in the study of museum communication and that this area would repay concerted research attention. I also identify benefits to print culture, book history and reader studies from research into the production and reception of museum books. As a commodity books offer commercial functions through the sale receipts that generate income and as physical objects they act as temporal devices, for example, as souvenirs or memorials, as archival or data sources and for reuse or recycling. Some of these features are relevant to both print and museum studies. In fact the intersection of the disciplines active in the study of museum publishing offers a rich area for study with potential for impact on both fields. For example, a book is an object imbued with plasticity, that is to say, within broad parameters the design and physical features that constitute a book may occur in unlimited combinations. While every book within an edition is identical between titles there is an infinite number of forms comprised of variations in typography, page layout, navigational structures such as title pages, chapter markers and section breaks and physical forms such as paper and binding. The design and form of one book type, the exhibition catalogue, has transformed in response to requirement for sales revenue. I conjecture that the changes traced in some, but not all, exhibition books result from the resolution of tensions between the agency of publishers with one aim for the book and that of curatorial scholars with a very different purpose.

\section{Publishing-scope, scale and museums}

Understanding the scope and scale of publishing will help place subsequent discussions into context. Publishing at its simplest is a process that orders, designs and disseminates intellectual property. Three main functions support this enterprise-editing, production and sales. Thompson (2012:19) expands these functions to encompass 'content acquisition and list building, financial investment and risk-taking, content development, quality control, management and coordination and sales and marketing'. One of the characteristic features of publishing is that these functions operate at a range of scales. By this I mean that a publishing enterprise may be part of a multi-national conglomerate, such as Penguin Random House with nearly 250 contributing imprints covering publishing for the academic and professional, fiction, illustrated life style and children's markets. At the other end of the scale a small multi-tasking staff may publish from an office. In between these extremes are independents such as Thames and Hudson with over 
2000 titles in print and large university presses such as Yale University Press with offices in New Haven and London. Clearly the annual output of books from publishing companies will vary according to the resources available and publishers make extensive use of external suppliers to expand production. For example, freelance individuals contribute copy editing and proofing services and digital technologies allow production to be carried out in any part of the world. Companies based in Asia offer overnight services in design and layout and companies based in Hong Kong, China and some Middle Eastern countries provide low cost printing services. However, museum books demand quality production with accurate colour printing and a short delivery lead time so that the books are in place for scheduled events such as the opening events of exhibitions. For these reason, many European museum publishers use printing companies in Europe.

These brief comments on trade publishing identify salient features of a creative industry which operates on a local, regional and global scale, that is composed of various commercial suppliers, influenced and disrupted by digital technologies and delivers products and services in a variety of formats to disparate markets. This is the context in which to understand the production of books by collecting institutions. The objective of this investigation is printed books. Digital publishing is considered where relevant but the focus is on print for the following reasons. First, books in printed format have proved resilient despite digital disruptions and remain viable as a publishing product, particularly for art collections. Second, the sale of printed books makes a considerable contribution to the funding of museums and galleries unlike online delivery of digital products which are usually offered as free resources. Digital dissemination of museum intellectual property is considered when it intersects with print, for example, in scholarly publishing where the results of research are usually distributed online or as downloadable files. This book omits some aspects of publishing by collections. It focuses on publishing for general or academic audiences by not the publication of materials for teachers or those that accompany school visits and I am not concerned with activity or work sheets for use by children and families in the museum. Multi-media resources aimed at engaging online audiences are not included and neither are apps. These omissions are based on the premise that such resources are usually free and therefore do not support museum income. A further feature of museum publishing influences the selection and presentation of case studies. Art institutions produce more books annually for the general public than collections such as those in natural history museums and science centres. For this reason examples and case studies are disproportionately concerned with publishing from art and historical museums. Science publishing is addressed where relevant and this is primarily in relation to research. 


\section{Interdisciplinary fields of study}

The current fields of study encompassing text, books, readers and print culture originates in the study of the dissemination of written language. As an emerging discipline contributions from various authors (see, for example, van der Vaal 2014; Willison 2009; Greetham 2009; Howsam 2006; Finkelstein and McCleery, 2005) offer perspectives on what constitutes this field and its relationship to other culturally animated areas of print. New disciplines coalesce from and carve out areas from established fields. The studies of books are equally required to argue for attention. Without doubt the study of books crosses traditional academic boundaries so that the investigation of publishing generally, and by museums specifically, is theorised by concepts from diverse fields. Print culture is a relatively recent scholarly endeavour and consequently draws on frameworks associated with more established disciplines that view a book as 'a written text, a material object, and a cultural transaction' (Howsam 2006:vii). These functions are addressed individually; in the first instance I consider museum books as commodities for sale. I report on the physical form of museum books that reflects the influences of agents such as curators, artists and sponsors. I then examine how museum books are read and consumed as cultural objects. In all this commercial and cultural study investigates the museum book through a lens of production and reception communication processes and through this order - text, material object, cultural entity-aim to understand the complex relationships active in museum publishing.

A theoretical frame from which to systematically investigate these functions is offered in Thompson's (2012:3-4) adaptation of Bourdieu's concept of a field as a 'structured space ... occupied by agents and organisations whose power ... depends on the type and quantity of resources or 'capital' they have at their disposal'. Fields are composed of 'different kinds and quantities of power and resources' and within these fields are found different 'practices ... competition, collaboration and reward'. Applying this concept to publishing we can see that fields correlate with the published products and markets such as the categories of publications listed earlier each with their specific characteristics and readers. The agents such as directors, curators, editors, museum retailers, sponsors and commercial publishers operated within 'complex relations of power, competition [and] cooperation' (4) and 'the power of any agent or organisation is dependent on the kinds and qualities of resources or capital that it possesses' (5).The following example demonstrates how agency, negotiation, power and resources coalesce in the publication of an exhibition catalogue and is presented to show how this characterisation is useful in comprehending the relationships at play in museum book production. In this case, curators are a starting point. As agents influencing the written and physical form of the book they exercise power in the negotiated processes of publishing. Curatorial writing draws on the scholarship that underlies their research roles in the creation 
and study of collections. Research undergirds the creation and presentation of exhibitions and catalogues and are part of a curator's remit. Turning to another agent in the production of exhibition books, publishers are tasked with producing these catalogues to budget and on schedule. They are also responsible for the sales of these book and the derived income to the institution and for this reason work towards a visually aesthetic book that offers text that is accessible for a general audience, and it is in the text, structure and form of the book that the negotiation and power plays out between these two agents. Curatorial writing in a style and register that is appropriate for an academic audience with the conventions of footnotes and appendices does not necessarily appeal to the general reader. Resolution of these different requirements for individual museum books occurs during the production processes and at department and director level, but these issues usually remain open to be played out in subsequent museum publishing projects.

This description characterises negotiations that are usually resolved at management levels above that of individual staff but may reoccur within the production of individual books. Outside of the institution, Thompson's frame is readily applicable to the power, agency and resources at play in the external links museum publishing operate with commercial trade publishing. This is particularly apparent in the production of art books where images, derived from the museum's collections are an essential resource in producing informative and engaging books. Ownership of copyright and the sale of reproduction rights are required negotiations that have a direct impact on the costs of production and retail price for art books and despite some resolution remains a source of some concern (Thorp 2006). In recent years, a few art institutions such as the Metropolitan Museum of Art, New York and The Getty, Los Angeles have adopted a policy allowing free use of images from works in their collections. Images are an essential feature of art books and this resource in whatever way it is shared remains an area of negotiation, power and agency. In most museums with concerted publishing programmes this enterprise is managed within the enterprise or income-generating spaces such as shops and cafes each with its own remit to return profits to the institution. The central chapters of this book offer a more detailed consideration of the agents, resources and negotiations apparent in exploiting the intellectual property inherent in a collection through publishing.

\section{The museum book-production}

Publishing then is characterised as occurring within fields comprising spaces with resources that are negotiated by individuals whose relative agency impinges on the resulting form of the book. This broader understanding of publishing now receives more definition as the book itself becomes the focus of our attention. Here we encounter a framework where production is viewed as worthy of research attention because it is the site where decisions are taken that affect the text, structure and 
physical nature of the book. McKenzie, who first drew attention to the agency of these processes suggests the term 'sociology of the text' to describe this area of study (1986). As interpreted by Johns (2013:396-7) research into print culture, contemporary or historical, needs to acquire an understanding of how 'the materials of literature (and any other cultural domain) were ... made and used' and that the book 'as a manufactured object is reliant on production processes' and its form is evidence for these processes. This is a potentially rich area of study for museum books since their form embodies the cultural agency of the collection and as an example of this the involvement of commercial sponsorship to support museum publishing is explored in Chapter Four.

In an adjunct to the form and associated functions of museum books, Finkelstein and McCleery (2013:67) recognise that the authority of books emerges from acknowledged authorship. This is to say, the name of the author is set out prominently in a book by accepted convention and this lends an authenticity to the text and its physical form which is turned to account by curators, museum directors and artists, among others. The authority of museum books both aligns with and draws on institutional authority. This attribute goes some way to explaining why contemporary artists embrace opportunities for a book to present their work that will freely circulate away from the museum for consumption by a wider, even global, audience. A further feature of the production process engenders confidence in the authenticity of texts; this is the consistency of an edition which in modern books results from editorial practices that check and fix the text so that each book is identical.

We will see in the following section that readers are viewed as independent agents in the interpretation of meaning. However, I suggest that factual content in nonfiction books is presented for consumption in a fixed, non-negotiable writing style and structure. This combined power influences readers' reception of museum books. From these observations, one might conclude that exhibition books, supported by the authority of both the museum and the book, provide curators with a vehicle with which to reassert their power, either knowingly or innocently, at the same time that they are being urged to relinquish control in exhibition spaces. That institutions and their books are both redolent of authority is discussed further in Chapters Four and Five.

\section{The museum book-reception and reading}

Despite this similarity across editions derived from consistent production practices, fiction is recognised as offering the potential for varied readings (see, for example, Radway 1984) and Barthes' declaration that 'the birth of the reader must be at the cost of the death of the author' (1977:148) draws attention to a theoretical framework from literary studies that identifies the reader as the final arbiter of 
meaning from written language. McKenzie's (1986) ideas concerning the social functions of books recur when we turn our focus on reading and readers because the material form of the text and the physicality of the book influences reading and the way books are utilised in the lives of their owners; so we have two entities to consider each with an impact on communication: the book and the reader. Reading is emphasized as an intellectual process of interpretation that is assisted by features in the book such as the typography, page layout and structural indications such as headings, sections, chapters that signpost readers' passage through the text (Finkelstein and McCleery 2013:102). While the making process generates these signs, their reception is dependent on the interpretive strategies of the reader. Reading also requires familiarity with typographic and format conventions acquired during the process of learning to read. How language is presented in written form and how these signs direct the reader's understanding is relevant to the reception of all texts but the reception of non-fiction has received less attention from theorist and definitive statements on the interpretive strategies of readers are as yet available. The complexity of academic texts such as art catalogues makes this interest particularly relevant to museum publishers. Without evidence to the contrary it is appropriate to ask whether the structured presentation of nonfiction - the type most commonly published by museums-allow readers fewer interpretive opportunities and that this combined power influences readers' reception of museum books. From these observations, one might conclude that exhibition books, supported by the authority of both the museum and the book, provide curators with a vehicle with which to reassert their power, either knowingly or innocently, at the same time that they are being urged to relinquish control in exhibition spaces. The impact of form and writing on the reception of exhibition books is explored in the central chapters.

There remain two areas of relevance to this study of museum publishing that need our consideration before moving into the structure of the book itself. The advent of digital technologies during the late $20^{\text {th }}$ century in the dissemination of knowledge is relevant to our interest in museum publishing which is covered following our consideration of the impact of museums and books in the development and construction of knowledge.

\section{Knowledge construction-museums and books}

A synergy between museums and books is apparent in the construction of knowledge in both the arts and sciences. Collections are active in the construction of knowledge and books hold and disseminate information; together they act as sites of discipline construction (Whitehead 2009; Knell 2007). A full understanding of the role of print in the development of scientific knowledge is a topic that encompasses many fields of study: Keighren (2013:no page numbers) points to territories and questions of relevance to print culture, science and their reciprocal influences: 
The intimate, not to say constitutive, relationship connecting science and print has proven to be fecund territory for scholars in the history of science, book history, and historical geography concerned with the production, circulation, and reception of knowledge. That the technologies and cultures of print have shaped, whilst being shaped by, science as a communicative process has encouraged attention to the role of printed books, scholarly articles, maps, engraved images, and other forms of inscription, in processes of knowledge making and dissemination. For science and for print, questions of authorship and authority, standardization and fixity, transmission and reception have often gone hand-inhand. So great is print's perceived significance to science in the modern era, it is often presented (alongside empiricism) as science's sine qua non.

From within this large field Johns (2013) directs our attention to specific actions of printed materials, two of which are directly relevant to our interest in books from collections: the circulation of information and images as a means of representation. Creation of knowledge and its circulation is not solely dependent on collections and their curation but we can see the impact of natural history museums on the formation of disciplines such as zoology, botany and palaeontology, through the institutions' acquisition, sorting, categorisation and description of specimens. Texts emanating from these $19^{\text {th }}$ century institutions produced, disseminated and changed the nature of knowledge while readers through their consumption of these texts were able to join and then contribute to a community of knowledge. Examples linking museums, publishing and the circulation of scientific knowledge by the Natural History Museum, London and the Smithsonian, Washington, DC are discussed in Chapter Two.

The importance of images in contemporary museum books is referred to in later chapters where visual representation of art and natural history specimens clearly attracts readers to books. Images also play a large part in the dissemination of knowledge. Historically, the presentation of identical graphics though the use of wood-block prints allowed 'a different orientation to knowledge because it made possible the preservation of information, its accumulation, comparison and correction and its wide dissemination.' (Ogborn and Withers 2010:6). Accurate illustrations enabled comparative studies and contributed to scientific identification which in turn aided the acceptance of accurate and identification of specimens. However, while many historical publications included excellent illustrative materials the reproduction of images was costly and often required external funding from either governments or private individuals. The resources required to publish Banks' 
Florilegium -images of Australian flora from the voyages of James Cook-are set out in the case study Realising intellectual property two hundred years. The study of art, both historical and contemporary, could not take place without the reproduction of images circulated in books. The books that shaped art history as a discipline and contributed to the canon of Western art are discussed by Shone and Stonard (2013:231-59). The controversies and ambiguities that enliven the canon derive from books and from the formation and presentation of collections in institutions (Perry and Cunningham 1999:16). Published texts from museums play their part in spreading knowledge of these collecting practices and the agency of publishing in this community of practice is apparent in case studies that Perry and her collaborators examine as part of the canonical traditions in eighteenth and nineteenth century British art. In Chapter Two we will see that illustrated catalogues associated with the dissemination of aristocratic collections in $17^{\text {th }}$ and $18^{\text {th }}$ century Europe influenced the development of art history.

\section{'Dead' books}

Are books still thought to be dead? Some years ago statements in the media and concerns expressed in scholarly publications suggested that printed books were no longer a viable means of communication. These cries were usually accompanied by calls for the resurrection of print. A period of declining print sales and the increasing sales figure of e-books particularly for novels appeared to support these predictions. The benefits of digital delivery, e-reading and the democratization of production that would enable scholarly monographs to be more widely consumed and enable their salvation (Epstein 2001) were widely heard. However, as evidenced previously in the advent of new technologies, the older media survives. Recent statistics (Altersept 2015) indicate that the turn to digital reading has slowed, that print remains resilient and sales of printed books have increased (Tivnan 2018).

It also appeared that ebooks were appropriate for some forms of text but less appropriate for others. Museum books for the general public and those for temporary exhibitions are categorised by the publishing industry as illustrated nonfiction, a form of publishing where digital platforms such as tablets work less well than they do for fiction (Christiansen 2014). During the increase in digital book production, illustrated art books remained resolutely associated with the medium of print. However, digital formats and digitization is increasingly relevant to collections and the impact of the digital/print seesaw leaves museum publishers 'in a cultural space where print jostles with other media, where it no longer commands prime spot in cultural terms' (Finkelstein, 2010:65). However, it seems likely that the printed book will survive in parallel with digital distribution as 'no other medium confers such intellectual respectability' (Powers 2002:156) and there are readers, including digital natives, who enjoy and are committed to purchasing and reading physical books. 
Most publishing enterprises have integrated digital technologies into their production processes. However, the disruption to print as a delivery medium evident a few years ago has been weathered and physical books remain commercially viable. Similarly, collecting institutions utilise digital technologies such as websites, social media, apps, ebooks and print-on-demand for audience development, engendering communities and sharing intellectual property (Parry 2005, 2007; Marty 2007, 2008). The digital medium is becoming paramount for public outreach and now provides access to the previously unavailable parts of collections. Legacy publishing projects repurpose printed books for the online environment and the digitization of collections enhance scholarly endeavours. However, the printed book is alive and well and remains central to the communication strategies for collections. For these reasons printed books from museum and art galleries, libraries and other collections are central to this book as shown in the following chapter outlines.

\section{The organisation of this book}

Each of the following chapters include case studies based on either literature, observation or interviews with museum and gallery staff associated with publishing. These aim to clarify through example issues presented in examining a theoretical stance, established practice or developments in the production of or response to books. The purpose is to emphasis through recounting specific situations how print provides for the funding, circulation and interpretation of collections and enables the cultural utilisation of books by institutions and their personal use by museum visitors and readers. Here are the chapter outlines in more detail.

The historical overview of museum publishing in the next chapter establishes the uses to which the books were put in service of the collections and their owners including the income from the sale of printed materials. Books as physical objects offering content, commercial and cultural advantages are long standing adjuncts to libraries, museums, galleries, herbaria, botanical gardens so that the origins of museums and advent of printed materials coincide in the formation of collections in early modern Europe. The formation and consumption of collections from cabinets of curiosity to blockbuster shows are associated with books produced for the purpose of personal aggrandisement, celebration, circulation and information. These case studies demonstrate the linkages between the formation of the collection and its public dissemination through the medium of print:

Circulating a paper collection-Museo Cartego in early modern Europe.

'A record of knowledge and an angle of interest'-Publishing at the Victoria and Albert Museum, London.

Wonderful things - the blockbuster arrives.

Chapter Three establishes the scope of publishing enterprises associated with collections through a review of the contemporary production and sale of books by 
museums, art galleries, libraries, science and heritage centres, historic houses, zoos, botanical gardens and commercial galleries. Figures for publishing from annual reports are presented to demonstrate the contribution made towards the financial health of institutions. National museums and art galleries are the largest producers of books and the contribution of publishing to funding focuses on these institutions. The commercial aspects of publishing connected with collections and the impact that sales figures impose on the format of the book are introduced. While economic purposes reign, publishing is also a culturally influential enterprise and this aspect is addressed. These case studies offer practical examples of commercial and cultural production of books for museums:

Realising intellectual property 200 years on-Bank's Florilegium at the Natural History Museum, London.

Re-opening, re-ordering, representing-the Guide to the Rijksmuseum, Amsterdam. Publishing for museums-Thames and Hudson, London and New York. Books for people and purposes - MoMA's entrepreneurial opportunities. [page ??] Privileging the director's voice-explaining the permanent collection [page ??] Chapter Four considers the contribution of producers-curators, directors, artists and sponsors - and their uses of books for career development, individual celebration and career recognition and alignment with the institution. Case studies look at specific issues for these individuals and their uses of books:

The curators' voice in print, online and app-interpreting collections at the Freer/Sackler Gallery of Art, Washington, DC.

What artists want-Alison Watt and her catalogue from the National Gallery, London.

Fifteen years on-Trade Routes Revisited in Cape Town and Johannesburg. Leading on from these personal uses of books, Chapter Five addresses the scholarly publishing that emanates from research active institutions and individuals. Digital delivery of scholarship and research provides the anomalous situation whereby it fulfils the public remit to full access to scholarship and research yet takes away an essential source of funding at a time when museums and art galleries are being required to reduce reliance on government funding. The impact of digital technologies on the dissemination is considered in case studies:

Getting scholarship online-the catalogue and Getty.

Giving it away-The Metropolitan Museum of Art, New York shares legacy books online.

Capturing born digital-archiving online art history resources.

Chapter 6 addresses the reception of museum publications, particularly art catalogues by the general public. Literature reviews influencing research in visitor and readership studies introduce the rewards of book ownership as indicated by 
visitors to four exhibitions in London institutions. Memorial function redolent in books is suggested as a partial explanation for the buoyant sales of art books. Case studies consider the contribution to audience development offered by book publishing:

Hooking them early-children's publishing for collections.

Every three years - publishing for the Asia Pacific Triennial, QAGOMA, Brisbane. Reconstructing catalogues-Making the book our own in Singapore.

A range of resources-matching in-gallery texts to visitor characteristics at the Van Gogh Museum, Amsterdam

Engaging millenials with graphic novels.

Chapter Seven makes the case that the intersection of museum and publishing studies has the potential for a rewarding area for future research and the suitability of museums and galleries for research into printed commodities is emphasized. Museum staff are familiar with evaluation procedures for public programming and the requirements of audience research. In line with this point, the distinct nature of museum/art gallery publishing is established with a particular reference to the benefits of the museum/gallery as a research locale for examining aspects of the production and reception of printed texts (the museum book is authored, designed, project managed, sold and consumed within its producing institution). Museums as entities that commission, produce and sell books offer publishing studies a location where all aspects of the enterprise are conducted and non-fiction which forms the bulk of books produced has been less well studied than fiction. Studies into visitors' experiences has failed in the past to effectively follow visitors after they leave the museum despite an acknowledgement of the importance of this period in consolidating learning. Taken together, these points suggest that a concerted approach to studying the reception of museum publishing offers a rich seam for research. Methods are suggested with the potential to address this area of importance to museums and print culture. The study of museum and gallery publishing is absent from museum, heritage and art gallery studies as summarised in and the contribution the title offers in generating a better understanding the nature of production and reception of text associated with exhibitions, artists, and collections. The study of these effects draws on publications as a permanent record of these events without recognising that publications are not direct reflections of the show, or the visitor's experience because of the variety of influences acting on their production. A single case study is offered to support this chapter:

Two centuries of guide books - publishing at the Sir John Soane Museum.

The final chapter suggests future developments in museum and gallery publishing. The rise of publishing by commercial contemporary art galleries and the advent of roles in museum management structures that stress the presentation of intellectual 
property as 'content' and demote the format of its distribution is considered. Two case studies suggest possible trends in production and form:

We learn to dance together-international scope of art gallery publishing at Hauser \& Wirth, Zurich, London, Bruton, New York, Los Angeles, Hong Kong.

Recycling intellectual property-Facsimiles at The Bodleian Library, Oxford, UK.

Creation, content and critique - dialogue in a virtual space

\section{Conclusion}

Museum and gallery publishing produces artefacts that represent the institution and its staff, contribute to the authority and agency of the museum, engage audiences, disseminate scholarship, promulgate the canon and market the collections and exhibitions. For many institutions the sale of printed books contributes funds to their annual income. The fields intersecting and influencing an understanding of print culture are recognised in Darnton's (1982:67) often quoted comment that the study of book history might benefit by establishing a distance from the interdisciplinarity run riot'-an observation that might be applied equally to museum studies. When the two fields coalesce, the complexity is even more difficult to contain and address but together they form a rewarding area for analysis. Darnton suggests that defining an 'ordered landscape' offers a start through which to generate an understanding of the interconnections between these complex fields. In setting out relevant theories from the fields museum and print studies and identifying similarities between them, this book aims to contribute to an ordering from which to study these areas. My hope is that others will see the potential for research within and across these fields.

Theories relevant to print culture and book history studies contribute to understanding of the production and reception of books and the impact these processes exert on institutions and individuals. Books exude authority and through this and other attributes such as aesthetics and physicality influence the reception of the texts by their consumers. Books have a long and convoluted history with resonances in social, political, literary, technological and cultural studies. The impact of scholarly publishing by collections can be located in the history of science, in art history, in heritage and literary studies. Since publishing utilises written language and books present individual elements in a cohesive whole the analysis of text discourse is another arena which contributes to our understanding of the production and dissemination of intellectual property and its influence on collecting institutions. When considering audiences in the form of visitors to museum and readers of books the field of communication is relevant. In museum studies, the publication of scholarly and general texts in both print and digital form influences curatorship, collections, archives, conservation, finance, administration, marketing and, most obviously, exhibitions. In all a diverse range of theoretical studies exert their influence on our particular interest in museums and their publications. 
We will see in the ensuing chapters, the purposes that books fulfil for institutions, curators, artists and commercial sponsors, the means by which scholarship is communicated to specialist and general audiences and the ways in which readers receive these specialised texts. The distinct attributes I argue for the products of museum publishing call for more attention and I start with an historical background in the next chapter. 